\title{
Bulkamid (PAHG) in mixed urinary incontinence: What is the outcome?
}

Stefan Mohr, $1{ }^{*}$

Phone +41316321010

Email stefan.mohr@insel.ch

Christine Marthaler, 1

Email christine.marthaler@insel.ch

Sara Imboden, 1

Email sara.imboden@insel.ch

Ash Monga, 2

Email ashmonga212@gmail.com

Michel D. Mueller, 1

Email michel.mueller@insel.ch

Annette Kuhn, 1

Email annette.kuhn@insel.ch

1 Department of Obstetrics and Gynecology, Inselspital, Bern University Hospital, University of Bern, Effingerstr. 102, 3010 Bern, Switzerland

2 Department of Obstetrics and Gynecology, Princess Anne Hospital, Southhampton, UK

\section{Abstract}

\section{Introduction and hypothesis}

Mixed urinary incontinence (MUI), defined as mixed symptoms of stress urinary incontinence (SUI) and overactive bladder (OAB), is a difficult entity if conservative treatment has failed. Cure rates are low compared with SUI, particularly the OAB component, may deteriorate after sling insertion. Bulking agents pose an appealing alternative for the treatment of 
MUI. They have shown beneficial effect in small case studies, but larger series are lacking. The aim of this prospective study was an analysis of treatment efficacy and safety profile of the bulking agent, Bulkamid, in female patients with MUI.

\section{Methods}

One hundred fifty-four women with MUI symptoms (components of SUI/OAB within the limits of $60-40 \%$ either way) received bulking therapy with polyacrylamide hydrogel (Bulkamid). Patients were followed-up 3 months postoperatively. Primary outcome was the domain Incontinence impact on the King's Health Questionnaire (KHQ). Secondary outcomes were the other KHQ domains, visual analog scale (VAS), and International Continence Society (ICS) standardized pad weight test as objective measurement of incontinence.

\section{Results}

Statistically significant improvements were found for all KHQ domains, pad weight test, and the visual analog scale (VAS) before and after bulking. Overall complication rate was $13 \%$.

\section{Conclusions}

This study has shown improvement in MUI after bulking therapy according to both subjective and objective outcomes. We can advocate bulking therapy for treating MUI, as it is simple and safe and shows both objective and subjective improvement and relief. Long-term results (up to 1 year) are awaited.

\section{Keywords}

Bulking agent

Bulking therapy

Periurethral bulking

Stress urinary incontinence

Overactive bladder

Mixed urinary incontinence 
This paper was accepted for oral presentation at the 2016 IUGA Scientific meeting.

\section{Electronic supplementary material}

The online version of this article (doi: 10.1007/s00192-017-3332-5 ) contains supplementary material, which is available to authorized users.

\section{Introduction}

Mixed urinary incontinence (MUI) is defined as involuntary loss of urine associated with urgency and with effort, physical exertion, sneezing, or coughing [1]. It is a combination of stress urinary incontinence (SUI) and overactive bladder (OAB) and is prevalent in $20-36 \%$ of women [2]. The pathophysiology of MUI is poorly understood, which impedes choosing appropriate therapies [2,3]. Treatment is controversial, and an individual strategy is needed, since women with MUI comprise a heterogenous group of patients [4]. Initially, a conservative approach is advocated [4], treating the most bothersome component first [2]. If surgery is needed, urodynamic evaluation is recommended [4], although the role of urodynamics in MUI is also controversial [5].

Retropubic colposuspension is effective for treating SUI, but de novo urge and a higher risk of pelvic organ prolapse (POP) are known side effects [6]. Midurethral slings are safe and efficacious treatment options [7].

Transobturator tape seem to have a good subjective success rate, and frequently, urgency urinary incontinence (UUI) resolves [8]. The main reason for dissatisfaction with a sling in general is overactive bladder [9]. Even if SUI is cured surgically, patients need to be informed that OAB symptoms might persist or even deteriorate [4].

Evidence is available for treating UI with weight loss, SUI with slings and urethropexies, and UUI with anticholinergics. However, there are neither clear diagnostic criteria nor management guidelines for MUI, and evidence for treatment is lacking [2]. Hence, treatment alternatives are required in patients with MUI. Peri- or transurethral bulking is a simple method to treat incontinence in a subset of patients showing objective and subjective symptom improvement [10], and Bulkamid has favorable results in a pooled population of SUI and MUI [11]. The aim of this study was to specify the efficacy of the periurethral bulking agent Bulkamid (polyacrylamide 
hydrogel; PAHG) in patients with exclusive MUI.

\section{Materials and methods}

Between January 2010 and October 2014, 154 women with MUI were treated by periurethral bulking with polyacrylamid hydrogel (PAHG; Bulkamid) in the University Women's Hospital, Department of Urogynecology, Bern, Switzerland, and the Princess Anne Hospital, Department of Urogynecology, Southhampton, UK. To be included in the study, components of SUI and OAB had to be within the limits of $60-40 \%$ either way to avoid predominance of one aspect. This is in contrast to our previous study in which only patients with SUI were included [10]. Primary outcome was the domain of Incontinence impact of the King's Health Questionnaire (KHQ). Secondary outcomes were the remaining domains, visual analogue scale (VAS), and International Continence Society (ICS) standardized pad test as objective measurements of incontinence. Subjective and objective outcomes were measured before and 3 months after intervention. To gather a rather homogenous group of patients with balanced MUI, they rated the stress and OAB components of their bladder problem with the limits of 60:40\% to either side. Demographic data of age, body mass index (BMI), parity, and menopausal status were noted. The study was approved by the local ethical committee, and all patients gave informed consent to participate (KEK 127/2009).

The King's Health Questionnaire (KHQ) determines quality of life (QoL) and is widely used in patients with incontinence [12]. The questionnaire is validated in several languages, including German [13], and is used to assess various domains, including general health perception, role limitation (e.g., household, cleaning, shopping), physical and personal limitation (walking, sports, travel, social life, relationship, sex, family life), emotions (depressed, anxious, nervous, feeling bad about oneself), sleep (feeling worn out, tired), and incontinence impact (pad usage, need to change underwear, restrict drinking, fear bad smells). Additionally, bladder problems are specified in the KHQ as questions for frequency symptoms, nocturia, urgency, SUI episodes, coital incontinence, urinary tract infections (UTI), and bladder pain exist. The scores for each domain range from 0 to 5 and 1 to 5 , respectively, are totalled, and a change of at least five points is considered significant [13]. Subjective outcome was further assessed with the patients judging their incontinence severity on a visual analogue scale (VAS), a validated tool to assess health and satisfaction, pain, attitudinal attributes, and QoL [14]. 
Additionally, as objective measurements, a standardized 2-h in-office pad test was performed according to ICS recommendations [15]. Before and after intervention, UTIs were excluded using dipstick screening and infections or bacteriuria was treated. For the injection procedure, women were placed in the lithotomy position, 5-10 $\mathrm{ml}$ of $1 \%$ lidocaine were injected in the periurethral tissue at 4 and 8 o'clock, and the bulking agent was injected transurethrally into the submucosa under cystoscopic control. Two to three deposits were placed in the midurethra at 6,2 , and 10 o'clock, and quantity was determined by the surgeon's judgement of coaptation. Needle position was corrected if it was suspected to not be in the mucosa or if there was extravasation of the bulking agent. If coaptation was considered appropriate, the bladder was emptied. Patients received a single-shot antibiotic prophylaxis with Co-amoxicillin and were discharged if postmicturition residual volume was $<100 \mathrm{ml}$. Evaluation was performed 3 months postoperatively. All adverse events were monitored and registered. If the procedure was unsuccessful, the woman was offered a further injection after 6 weeks. For statistical analysis, Graph Pad Prism version 5.0 for Windows was used (Graph Pad, La Jolla, CA, USA) to calculate Student's $t$ test and Wilcoxon signed rank test.

\section{Results}

One hundred and fifty-four patients were injected with Bulkamid periurethrally. Demographic data demonstrated a median age of 68 (range 29-93) years, a median BMI of $24 \mathrm{~kg} / \mathrm{m}^{2}$ (range 17-32), and a median parity of two (range 0-9). Seven patients were pre-, six peri-, and 141 postmenopausal. For 12 patients, menopausal status was lacking. In our collective, 11 patients had previously undergone Burch colposuspension, nine a retropubic sling, and three a transobturator sling. Sixteen patients were lost to follow-up, whereof two died of unrelated causes, 12 moved to other places, and two were lost because of unknown reasons. Analysis with the Wilcoxon signed-rank test for non-normally distributed paired data showed statistically significant improvements for all domains of the KHQ before and after bulking (Fig. 1, all $p<0.0001$ ). Likewise, pad-weight test (Fig. 2, $p<0.0001$ ), and the VAS as a sujective measure of severity (Fig. 3, $p<0.0001$ ) improved significantly after the intervention.

\section{Fig. 1}


Results of the King's Health Questionnaire: all domains were significantly improved after bulking therapy ( $p<0.001$, Wilcoxon signed rank test)

King's Health Questionnaire

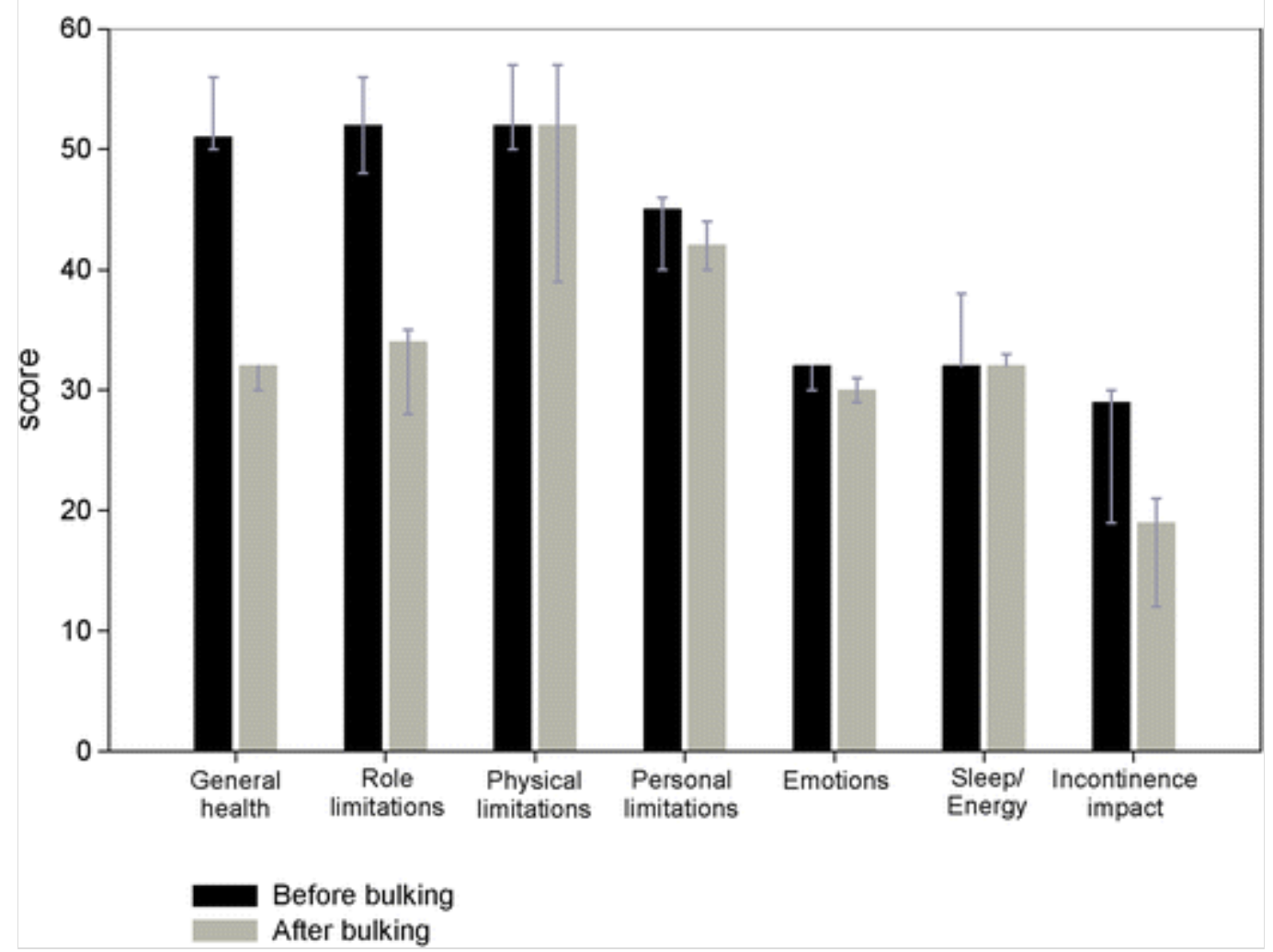

Fig. 2

Pad-weight test results improved significantly after bulking therapy $(p<0.001$, Wilcoxon signed-rank test) 


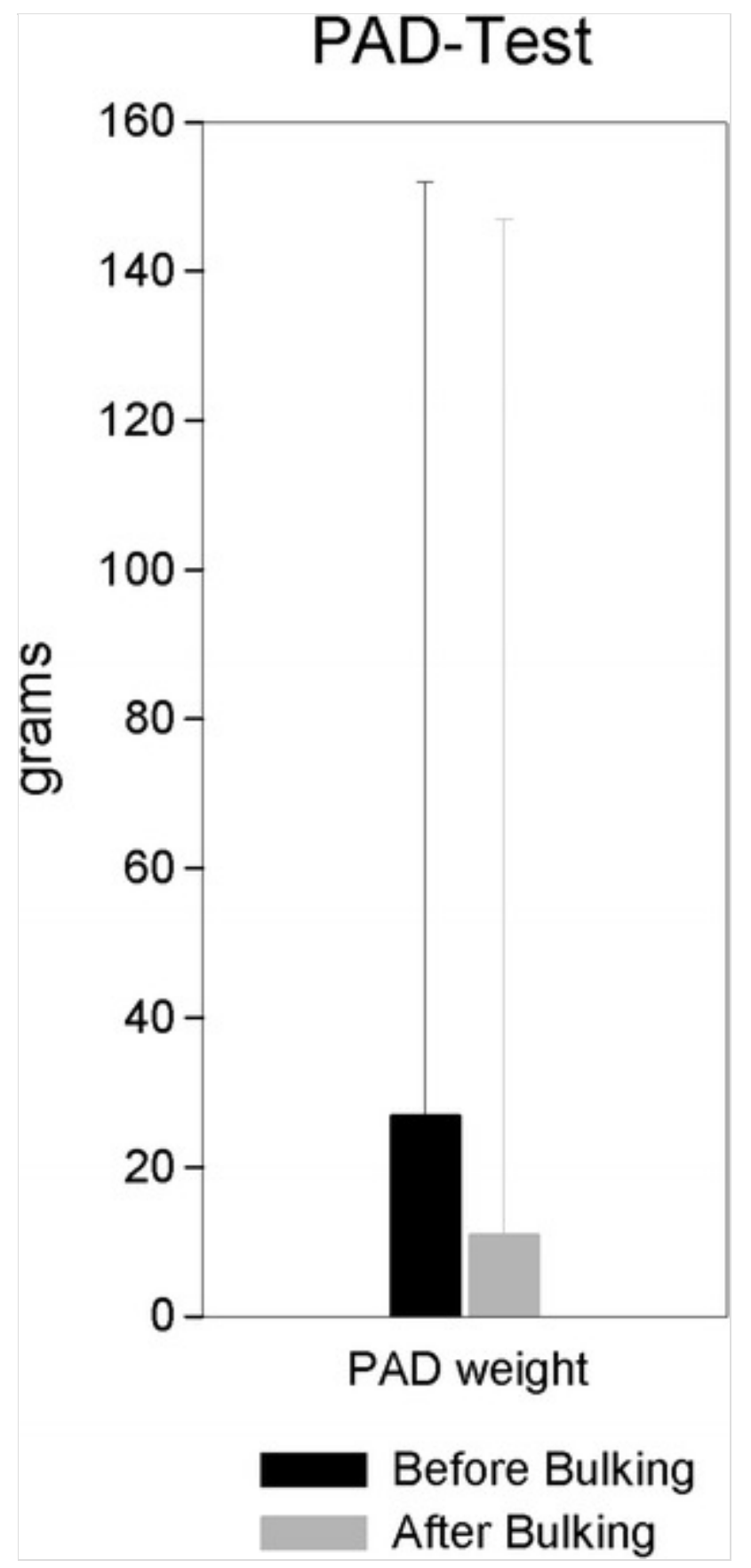

Fig. 3

Visual Analogue Scale results as a subjective measure of incontinence severity with a significant improvement $(p<0.001$, Wilcoxon Signed Rank Test) 


\section{Visual Analogue Scale}

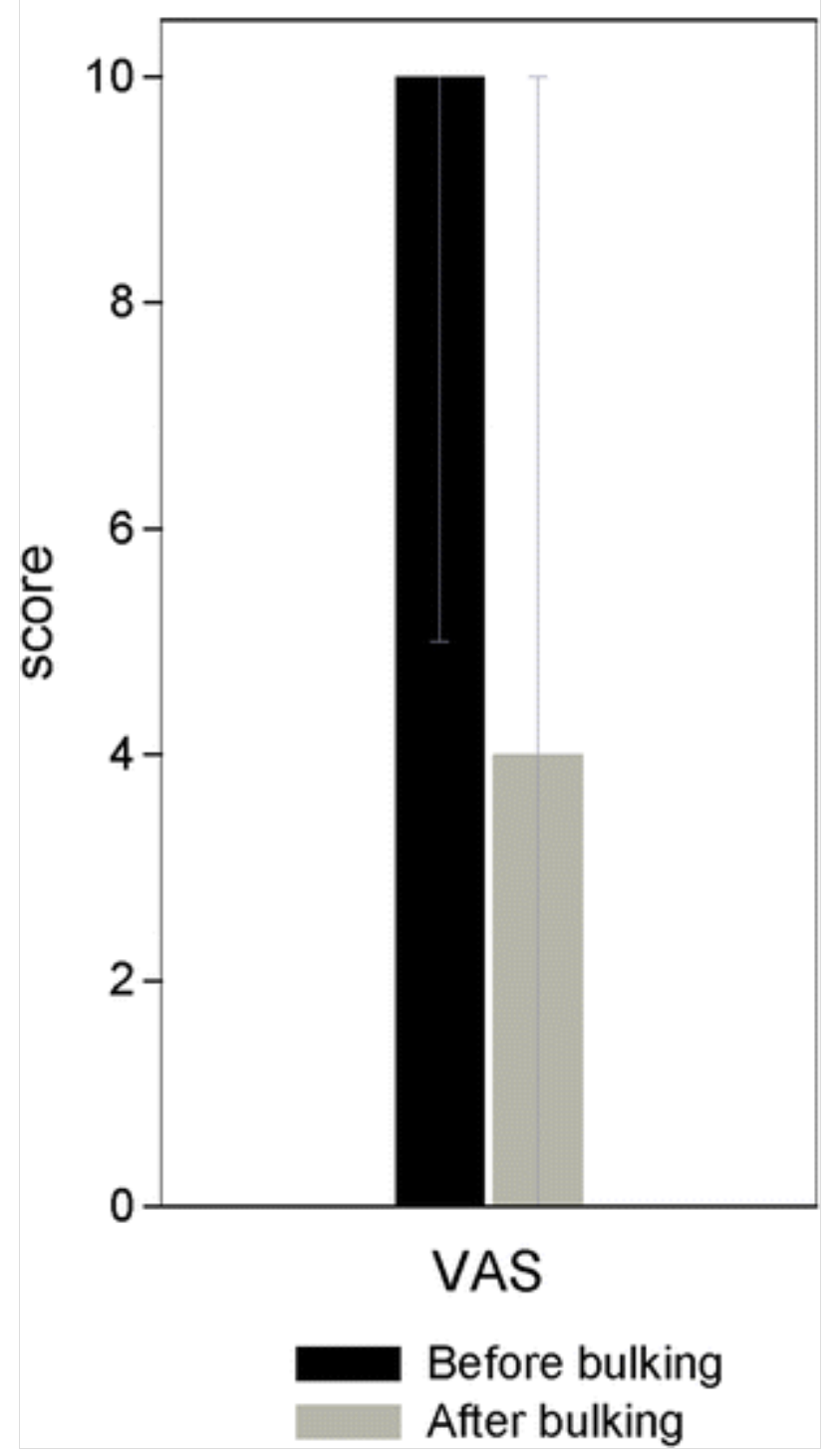

The overall complication rate was $13 \%$ due to lower UTIs $(n=12)$, temporary retention $<48 \mathrm{~h}(n=3)$, and pain requiring additional pain medication $(n=4)$.

\section{Discussion}

We show that bulking therapy is a beneficial and valuable alternative to surgical treatment in the rather heterogenous group of patients with MUI. Pad-weight tests showed that patients were not dry after the injections but that leakage was significantly improved, and their satisfaction mirrors QoL improvement on the VAS and KHQ results. Additionally, it also suggests that patient satisfaction is not necessarily dependant on complete dryness.

In MUI, treatment decisions are less obvious than in either SUI or UUI patients, and alternative therapies are needed [2]. Periurethral bulking therapy has been used for for years to treat SUI and shows improvements even over 
the long term [16]. Recurrence rates are higher after bulking therapy than after other incontinence surgeries but should be considered as an alternative treatment [17]. Bulking therapy is simple, safe, and shows both objective and subjective improvement and relief in selected SUI patients [10]. Although a Cochrane Review concluded that evidence for urethral injection therapy to treat UI in women remains insufficient to guide practice [18], the minimally invasive nature, efficacy, and safety of periurethral bulking with PAHG favors its use in the correctly selected patient $[19,20,21]$.

Moreover, bulking therapy is used to manage failed SUI surgery [22, 23], especially in patients with intrinsic sphincter deficiency [24], and PAHG is used in this respect with good outcome and low complication rates [24, 25]. Repeat midurethral sling after primary sling failure seems to have a lower risk of failure than bulking therapy [26], but the latter is more cost effective than midurethral slings in patients without urethral hypermobility [27]. Furthermore, urethral bulking therapy has been described as a valuable treatment option in SUI after pelvic radiotherapy [28].

In MUI, conservative treatment focusing on the most bothersome component is the first therapeutic step [2,4]. If conservative treatment fails, surgical alternatives become necessary. Petros suggested that in MUI, uncoupling urge from stress might separate two different symptoms with possibly different etiologies, and these should therefore be treated separately [29]. However, our results suggest that bulking therapy might ameliorate incontinence symptoms holistically. We show significant improvements in both subjective (VAS, KHQ) and objective (pad-weight test) outcomes. Patient-reported outcomes are particularly important, as they better reflect patient satisfaction than do mere objective measurements [30]. Although complications of bulking therapy are not to be neglected [30], side effects were few and mild. Additionally, bulking therapy is minor surgery, with the possibility of using local anaesthetic only, which is usually appreciated by patients.

Strengths of this study are the rather large number of patients, especially as it is the first concentrating on bulking therapy in MUI patients specifically. Advantageous is the inclusion of both objective and subjective outcomes obtained with validated tools, since this might more accurately reflect the patient's goals [10].

A weakness of this work is the lack of urodynamic data measuring bladder function before and after treatment; however, we felt urodynamic data were 
not of great importance in this study. Also, due to the strict inclusion criteria, particularly with the mixture of SUI and OAB being relatively equal, the study was lengthy. By incorporating urodynamics, recruiting patients requiring invasive tests may have lengthened that period. We felt such information-except possibly in patients with detrusor overactivity—was unnecessary for our study. A further weakness is the lack of accurate estimation of the influence of bulking therapy on the urge component. VAS was used to reflect global disturbance for assessing incontinence severity in general. Results of our study do not allow a breakdown of urge and stress components; however, they allow us to make the conclusion that incontinence symptoms generally improve with bulking therapy, even in patients with MUI symptoms.

In conclusion, MUI patients are difficult to treat, since their symptoms are heterogenous and less well understood in general. Randomized trials in women with MUI are needed [2]. Nevertheless, bulking therapy is promising, simple, safe, and provides patient relief. Therefore, we can recommend its use to treat patients with MUI.

Compliance with ethical standards

Conflicts of interest None.

Electronic supplementary material

\section{ESM 1}

(JPEG $513 \mathrm{~kb}$ )

\section{References}

1. Haylen BT, de Ridder D, Freeman RM, Swift SE, Berghmans B, Lee J, Monga A, Petri E, Rizk DE, Sand PK, Schaer GN. An international urogynecological association (IUGA)/international continence society (ICS) joint report on the terminology for female pelvic floor dysfunction. Int Urogynecol J. 2010;21:5-26. doi: 10.1007/s00192-009-0976-9 . AQ1

2. Myers DL. Female mixed urinary incontinence: a clinical review. JAMA. 2014;311:2007-14. doi: 10.1001/jama.2014.4299 . 
3. Bandukwala NQ, Gousse AE. Mixed urinary incontinence: what first? Curr Urol Rep. 2015;16:9. doi: 10.1007/s11934-015-0483-0 .

4. Kammerer-Doak D, Rizk DE, Sorinola O, Agur W, Ismail S, Bazi T. Mixed urinary incontinence: international urogynecological association research and development committee opinion. Int Urogynecol J. 2014;25:1303-12. doi: 10.1007/s00192-014-2485-8 .

5. Rachaneni S, Latthe P. Does preoperative urodynamics improve outcomes for women undergoing surgery for stress urinary incontinence? A systematic review and meta-analysis. BJOG. 2015;122:8-16. doi: 10.1111/1471-0528.12954 .

6. Lapitan MC, Cody JD. Open retropubic colposuspension for urinary incontinence in women. Cochrane Database Syst Rev. 2016;2:CD002912. doi: 10.1002/14651858.CD002912.pub6 .

7. Wood LN, Anger JT. Urinary incontinence in women. BMJ. 2014;349:g4531.

8. Abdel-Fattah M, Hopper LR, Mostafa A. Evaluation of transobturator tension-free vaginal tapes in the surgical management of mixed urinary incontinence: 3-year outcomes of a randomized controlled trial. J Urol. 2014;191:114-9. doi: 10.1016/j.juro.2013.07.035 .

9. Aigmueller T, Bjelic-Radisic V, Kargl J, Hinterholzer S, Laky R, Trutnovsky G, Kolovetsiou-Kreiner V, Tamussino K. Reasons for dissatisfaction ten years after TVT procedure. Int Urogynecol J. 2014;25:213-7. doi: 10.1007/s00192-013-2213-9 .

10. Mohr S, Siegenthaler M, Mueller MD, Kuhn A. Bulking agents: an analysis of 500 cases and review of the literature. Int Urogynecol J. 2013;24:241-7. doi: 10.1007/s00192-012-1834-8 .

11. Toozs-Hobson P, Al-Singary W, Fynes M, Tegerstedt G, Lose G. Two-year follow-up of an open-label multicenter study of polyacrylamide hydrogel (Bulkamid(R)) for female stress and stress-predominant mixed incontinence. Int Urogynecol J. 2012;23:1373-8. doi:

10.1007/s00192-012-1761-8 . 
12. Kelleher CJ, Cardozo LD, Khullar V, Salvatore S. A new questionnaire to assess the quality of life of urinary incontinent women. $\mathrm{Br}$ J Obstet Gynaecol. 1997;104:1374-9.

13. Bjelic-Radisic V, Dorfer M, Tamussino K, Greimel E. Psychometric properties and validation of the German-language King's health questionnaire in women with stress urinary incontinence. Neurourol Urodyn. 2005;24:63-8. doi: 10.1002/nau.20092 .

14. Zhang XH, Xie F, Wee HL, Thumboo J, Li SC. Applying the expectancy-value model to understand health values. Value Health. 2008;11(Suppl 1):S61-8. doi: 10.1111/j.1524-4733.2008.00368.x .

15. Ryhammer AM, Djurhuus JC, Laurberg S. Pad testing in incontinent women: a review. Int Urogynecol J Pelvic Floor Dysfunct. 1999;10:111-5.

16. Mouritsen L, Lose G, Moller-Bek K. Long-term follow-up after urethral injection with polyacrylamide hydrogel for female stress incontinence. Acta Obstet Gynecol Scand. 2014;93:209-12. doi: 10.1111/aogs.12283.

17. Leone Roberti MU, Bogani G, Meschia M, Sorice P, Braga A, Salvatore S, Ghezzi F, Serati M. Urethral bulking agents versus other surgical procedures for the treatment of female stress urinary incontinence: a systematic review and meta-analysis. Eur J Obstet Gynecol Reprod Biol. 2015;189:48-54. doi: 10.1016/j.ejogrb.2015.03.025 .

18. Kirchin V, Page T, Keegan PE, Atiemo K, Cody JD, McClinton S. Urethral injection therapy for urinary incontinence in women. Cochrane Database Syst Rev. 2012;CD003881.doi: 10.1002/14651858.CD003881.pub3 .

19. Pai A, Al-Singary W. Durability, safety and efficacy of polyacrylamide hydrogel (Bulkamid $((\mathrm{R})))$ in the management of stress and mixed urinary incontinence: three year follow up outcomes. Cent Eur J Urol. 2015;68:428-33. doi: 10.5173/ceju.2015.647 .

20. Kasi AD, Pergialiotis V, Perrea DN, Khunda A, Doumouchtsis SK. Polyacrylamide hydrogel (Bulkamid(R)) for stress urinary incontinence in women: a systematic review of the literature. Int Urogynecol J. 
2016;27:367-75. doi: 10.1007/s00192-015-2781-y .

21. Sokol ER, Karram MM, Dmochowski R. Efficacy and safety of polyacrylamide hydrogel for the treatment of female stress incontinence: a randomized, prospective, multicenter north American study. J Urol. 2014;192:843-9. doi: 10.1016/j.juro.2014.03.109 .

22. MacLachlan LS, Rovner ES. Management of failed stress urinary incontinence surgery. Curr Urol Rep. 2014;15:429. doi: 10.1007/s11934-014-0429-y .

23. Zimmern PE, Gormley EA, Stoddard AM, Lukacz ES, Sirls L, Brubaker L, Norton P, Oliphant SS, Wilson T. Management of recurrent stress urinary incontinence after burch and sling procedures. Neurourol Urodyn. 2016;35:344-8. doi: 10.1002/nau.22714 .

24. Martan A, Masata J, Svabik K, Krhut J. Transurethral injection of polyacrylamide hydrogel (Bulkamid((R))) for the treatment of female stress or mixed urinary incontinence. Eur J Obstet Gynecol Reprod Biol. 2014;178:199-202. doi: 10.1016/j.ejogrb.2014.03.033 .

25. Zivanovic I, Rautenberg O, Lobodasch K, von Bünau G, Walser C, Viereck V. Urethral bulking for recurrent stress urinary incontinence after midurethral sling failure. Neurourol Urodyn. 2016; doi: 10.1002/nau.23007

AQ2

26. Gaddi A, Guaderrama N, Bassiouni N, Bebchuk J, Whitcomb EL. Repeat midurethral sling compared with urethral bulking for recurrent stress urinary incontinence. Obstet Gynecol. 2014;123:1207-12. doi: 10.1097/AOG.0000000000000282 .

27. Kunkle CM, Hallock JL, Hu X, Blomquist J, Thung SF, Werner EF. Cost utility analysis of urethral bulking agents versus midurethral sling in stress urinary incontinence. Female Pelvic Med Reconstr Surg. 2015;21:154-9. doi: 10.1097/SPV.0000000000000173 .

28. Krhut J, Martan A, Jurakova M, Nemec D, Masata J, Zvara P. Treatment of stress urinary incontinence using polyacrylamide hydrogel in women after radiotherapy: 1-year follow-up. Int Urogynecol J. 
2016;27:301-5. doi: 10.1007/s00192-015-2834-2 .

29. Petros PE. Mixed urinary incontinence--time to uncouple urgency from stress? Int Urogynecol J. 2011;22:919-21. doi: 10.1007/s00192-011-1449-5 .

30. Kotb AF, Campeau L, Corcos J. Urethral bulking agents: techniques and outcomes. Curr Urol Rep. 2009;10:396-400. 